\title{
Why would medical publishers not incorporate core bioethical values into their Ethics Guidelines?
}

\author{
Joseph Watine \\ Hôpital de la Chartreuse, Villefranche-de-Rouergue, France \\ Corresponding author: joseph.watine@ch-villefranche-rouergue.fr
}

\begin{abstract}
It is quite universally acknowledged by bioethicists, at least in the western world, that respect for the patients' autonomy, non-malevolence, beneficence, and justice (also called equity) are four core ethical values in medicine. The Ethics Guidelines of key journals in laboratory medicine are not explicit about the first three of these values, and even implicitly, they seem to miss values of justice. Health equity being one of the main objectives of public health policy across the world, we suggest that values of equity explicitly become part of the Ethics Guidelines of laboratory medicine journals. Biochemia Medica could show the way to other medical publishers by incorporating into its Ethics Guidelines these very important core bioethical values.
\end{abstract}

Key words: principle-based ethics; health care ethics; codes of ethics; editorial policies

\section{Introduction}

Medicine is more than pure science like, for example, physics, or mathematics: it is also underpinned by ethics and values at a society level (1). It is therefore paramount for editors of biomedical journal to adhere to ethical values. This is probably why more and more editors, including in the field of laboratory medicine, publish their own Publication Ethics Guidelines, such as Clinical Chemistry in 2009 (2), or Clinical Chemistry and Laboratory Medicine in 2013 (3), and/or become members of the Committee on Publication Ethics (COPE) (4), such as Biochemia Medica, Clinica Chimica Acta, Clinical Biochemistry, and a few others. The ethical principles and values endorsed by these journals are more or less adapted from those of international organizations such as the International Committee of Medical Journal Editors (ICMJE) (5), or COPE (4).
However, on careful reading of these Ethics Guidelines, including those of COPE, and of ICMJE, one can see that, apart from the endorsement of the Helsinki rules regarding the protection of subjects enrolled in studies, all the other principles and values related to publication ethics could suit any scientific journal from astronomy to engineering, etc.

Nevertheless, biomedical journals, including those in the field of Laboratory Medicine, are supposed to be more than purely scientific publications: they are also medical journals and as such their articles potentially influence medical practice and are likely to contribute to the improvement of public health. This is why the Ethics Guidelines of biomedical journals, including those of laboratory medicine, could be improved by more explicitly incorporating some of the quite established core ethical principles and values specific to the field of medicine. 


\section{Are there core bioethical values in medicine and health-care?}

It is quite universally acknowledged by bioethicists that respect for the patients' autonomy, non-maleficence, beneficence, and justice (also called equity) are four core ethical values in medicine (1), which are briefly defined below:

1. An autonomous patient acts in accordance with self-chosen plans, free from controlling interferences by others.

2. Non-maleficence imposes an obligation not to inflict harm on others. Many medical interventions may be both harmful and beneficial, but the harms should be proportionate to the benefits.

3. Beneficence means that health-care professionals contribute to the welfare of the patients in a way that makes sense to the individual patient.

4. Justice, also called equity, means that patients in similar positions should be treated in a similar manner. It is equally true that an injustice involves a wrongful act or omission that denies people resources or protections to which they have a right.

\section{Are these four core values dealt with in current Publication Ethics Guidelines?}

Implicitly the answer might be yes regarding nonmaleficence, beneficence, and respect for the patients' autonomy. For example, fabrication, falsification or mismanagement of primary data can obviously lead to deceptive articles having a strong potential to both, deceit patients' unbiased, informed decisions, and support interventions whose clinical harms may outweigh clinical benefits. However this is implicit, not explicit, which somewhat weakens these guidelines.

Health equity is one of the main objectives of public health policy across the world, as disadvantaged populations have poorer health, and poorer access to health care (6). This can be problematic including in rich countries, for example in the USA where worsening inequities have been reported by Krieger et al. between 1960 and 2002 (7). The
Office of Minority Health \& Health Equity of the Centers for Disease Control and Prevention (CDC) of the USA states on its front page on the Internet: "The future health of the nation will be determined to a large extent by how effectively we work with communities to eliminate health disparities among those populations experiencing a disproportionate burden of disease, disability, and death. Persistent health disparities in our country are unacceptable and correctable" (8). Regarding the coverage of equity in publication ethics, a statement similar to the one above from the $C D C$, and highlighting the commitment to the elimination of health disparity could help in clarifying the values that biomedical journal editors intend to deal with.

\section{Why might it be important to incorporate more explicitly core bioethical values into Publication Ethics Guidelines? A few examples.}

\section{1) The example of vitamin $D$ testing}

Vitamin $D$ testing has now become one of the most frequently ordered laboratory test across the world. For example in France, the frequency of testing has been multipled by more than 10 times in less than one decade, and vitamin $D$ is now on the verge of becoming the second most frequently ordered test just after blood cell counts. Clinically speaking, it sounds likely that these millions of tests have not harmed patients, but it also remains to be demonstrated that this huge increase in frequency of testing has improved the health of the public (9). The balance between clinical benefits and harms (or in other words between beneficience and malevolence) is therefore probably neutral. On the other hand, these numerous tests are now costing around 150 million Euros each year to the French collectivity, just for private labs. Such a waste of resource does conflict with values of justice, particularly in a country where millions of people are poor, and becoming poorer and poorer, many of whom becoming more and more unable to access to health-care. This huge increase of requests being very much connected with their promotion by writers of medical articles, it could therefore be supposed that if values of justice had 
clearly been part of Publication Ethics Guidelines, then perhaps these writers might have been less efficient in their work of promotion. For more details see section below entitled: "If core bioethical principles were explicitely incorporated into Publication Ethics Guidelines, then wouldn't such guidelines be difficult to implement?".

\section{2) The example of PSA (prostate-specific antigen) testing}

If 2,000 men were randomized into two groups of 1,000 men, one group being screened with PSA testing and the other one not being tested, then there would probably be as many men dying of prostate cancer in each group, or maybe according to the most optimistic trials: one death from prostate cancer would perhaps be avoided among the 1,000 screened men (10). In addition, 20 of the 1,000 screened men would be treated for prostate cancers which would not have caused symptoms. Five of these 20 men would have lifelong complications, including impotence and incontinence. Such statistics allow concluding that depending on patients' preferences, the test may be less beneficent than malevolent. In addition, PSA being a test that is mostly requested in a context of population screening, it is not surprising that it is among one of the most frequently ordered test in the world. For example, PSA testing in France is costing around 50 million Euros each year to the French collectivity just for private labs. This, again, raises issues of justice, just as in the vitamin D example above. In addition, taking into account the harms, and the very serious harms, done to respectively 20 , and 5 , of 1,000 patients tested, the question of informed consent of the patients (and therefore the question of whether or not their autonomy has been respected through fair informed consent) can very seriously be raised (10). For more details see section below entitled: "If core bioethical principles were explicitely incorporated into Publication Ethics Guidelines, then wouldn't such guidelines be difficult to implement?".

\section{3) The example of conflicts of interest (COI)}

It is more and more acknowledged by the medical community, that there is some room for improve- ment regarding the way $\mathrm{COI}$ of editors, of reviewers and of authors of biomedical articles are currently managed. Current Publication Ethics Guidelines generally require that authors of articles declare their COI, which are then published together with their articles. As an example of the shortcomings of current Ethics Guidelines, let us note that the declarations of the reviewers are generally not published with the articles that they review, and that the $\mathrm{COI}$ of the editors are even less often disclosed to the public. The fact that journals are more rigorous about $\mathrm{CO}$ with authors than with both reviewers and editors might reflects a lack of awareness about bioethical values. Why? The first answer that springs to mind, is that journals probably do not realize that COI have a strong potential to distort the evidence, which in turn can favor interventions whose maleficence may outweigh beneficence, with a higher risk that justice and respect for the patient's autonomy are not properly dealt with (see the vitamin D and PSA examples above). The $2^{\text {nd }}$ answer that comes to mind is that journals probably do not realize the paramount importance of virtues such as truthfulness and veracity for health professionals, researchers, and biomedical journalists. Having such virtues is indeed essential to foster trust, and if we define virtues as personal traits that contribute to a good climate of trust between people, where trust is taken to be acceptance of being to some degree and in some respects, in another's power, then it seems obvious that trustworthiness is essential in healthcare (1). Can we expect biomedical articles to be more beneficent than malevolent if the trust that people may have in this sort of biomedical evidence ends up being destroyed by authors, reviewers, or editors being less than fully open (even unintentionally) about their COI?

\section{Should medical writers (i.e. medical journalists) deal with the same bioethical values as health-care professionals?}

One could argue that core ethical principles in medicine (patient's autonomy, non-maleficence, beneficence and justice) cannot be easily applied in Publication Ethics, because medical practice in- 
volves working with patients, and assumes diagnosing, treating or preventing conditions or diseases, whereas medical journalism assumes writing and publishing papers mainly through medical journals, without interfering with patients. Although these view may make sense (except perhaps for medical writers or journalists who are also medical practitioners, which is the case of many of them), one could counter-argue that:

1. If medicine is more than science, then "Publication Ethics" should not remain synonymous anymore with "Medical-Publication Ethics" in the spirit of the writers, of the reviewers, and of the editors of medical articles.

2. If laboratory medicine is a medical discipline, then bioethical values should be dealt with in the same spirit in laboratory medicine publishing as in hepatology and hematology publishing, etc.

3. Writers, reviewers, and editors of medical articles, or in other words: medical journalists, should always bear in mind that their published articles may ultimately be used as evidence by the panelists who develop medical practice guidelines. The influence of evidence-based medicine is already significant on medical practice and this tendency is likely to be reinforced more and more in the future $(11,12)$.

\section{Should laboratory professionals deal with the same bioethical values as other categories of medical specialists?}

One could argue that although laboratory medicine is a medical discipline, laboratory medicine specialists generally do not deal with patients but rather with patients' samples (blood, urine, etc). Based on this general observation, one may conclude that core bioethical values should not apply to laboratory specialists. On the other hand, it may also be counter-argued that:

1. More and more countries in the world require that medical laboratories are accredited according to ISO 15189. For example, in France current laws say that the very few non-accredited laboratories that still exist in our country will have to close within the next few months. Being accredited according to ISO 15189 implies that patient's samples are not supposed to be accepted by the laboratory without a laboratory specialist being aware of the clinical context of the patient, so that this medical specialist can decide which tests are the most appropriate for an individual patient, and then be able to interpret the laboratory results for that individual patient. Therefore it can be said that laboratory specialists are more and more dealing with the patients in a way that resembles more and more to the way physicians deal with patients.

2. In some countries, for example in France, laboratory medicine specialists have an obligation to implement the guidelines which are published by their governmental organizations, for example in France the Haute Autorité de Santé (HAS). The HAS does not recommend to measure Prostate Specific Antigen (PAS) for screening prostate cancer unless the patient insists and gives his formal consent to be screened (10), and the HAS recommends to measure vitamin-D only in a limited number of specific circumstances (9). As already suggested above the bioethical values that are dealt with in these two French guidelines $(9,10)$ are mostly patient's autonomy, non-maleficence, beneficence and justice, which adds some weight in our view to our own recommendation regarding the incorporations of these core values into Publication Ethics Guidelines.

\section{If core bioethical principles were explicitly incorporated into Publication Ethics Guidelines, then wouldn't such guidelines be difficult to implement?}

Guidelines run the risk of being useless if they cannot be implemented. It sounds indeed reasonable and common sense, to argue that before one publishes guidelines, one should at least identify possible barriers to implementation, and propose practical guidance regarding how the guidelines will possibly be implemented. 
One such barrier could be a possible lack of knowledge about bioethics by many editors and by many reviewers, as well as by many authors. Therefore, one of the prerequisites for implementing such guidelines would be for medical journals to have some editors and/or some reviewers specialized in bioethics. This could include university degrees in bioethics, as well as training, experience, and publications within this discipline. We already illustrated above with a few examples (PSA testing, vitamin $D$ testing, and COI) that many editors of medical journals probably fail to incorporate core bioethical values into the papers that they publish and the potential adverse consequences of such failures.

As another example of possible guidance on how these four values should be incorporated into Ethics Guidelines that would be implementable, we propose that just like more and more editors-inchief require that papers published in journals contain a section entitled "Declarations of COI", papers should contain another mandatory section entitled "Ethics Review" where the possible impact of the paper regarding the four principles should systematically be examined by the authors. Thus both reviewers, and editors, using their special knowledge about, and training/experience in, bioethics would have an opportunity to systematically review such Ethics Reviews. This might ultimately lead to a better distinction, ethically speaking, between articles that are worth being published, and those that need to be revised, or rejected, or maybe published with Ethical Provisions.

In conclusion, Biochemia Medica could show the way to other medical publishers by incorporating into its Publication Ethics Guidelines these very important core bioethical principles.

\section{Acknowledgements}

To Rita Horvath (Sydney, Australia) for useful comments made to previous versions of this manuscript.

\section{Potential conflict of interest}

None declared.

\section{References}

1. Beauchamp TL, Childress J. Principles of Biomedical Ethics. 6th ed. New-York/Oxford, Oxford University Press, 2009.

2. Ethics Guidelines of Clinical Chemistry (2009). Available at: http://www.clinchem.org/content/55/1/1.full. Accessed November 21, 2013.

3. Ethics Guidelines of Clinical Chemistry and Laboratory Medicine (2013). Available at: http://www.degruyter.com/ view/supplement/s14374331_Publication_Ethics.pdf. Accessed November 21, 2013.

4. Committee on Publication Ethics (COPE). Available at: http://publicationethics.org/members. Accessed November 21, 2013; and http://publicationethics.org/resources/ guidelines. Accessed November 21, 2013.

5. International Committee of Medical Journal Editors (ICMJE). Available at: http://www.icmje.org/. Accessed November 21, 2013.

6. Oxman $A D$, Schünemann $H J$, Fretheim A. Improving the use of research evidence in guideline development: 12. Incorporating considerations of equity. Health Res Policy Syst 2006;4:24. http://dx.doi.org/10.1186/1478-4505-4-24.

7. Krieger $N$, Rehkopf DH, Chen JT, Waterman PD, Marcelli E, Kennedy $M$. The fall and rise of US inequities in premature mortality: 1960-2002. PLoS Med 2008;5:e46. http://dx.doi. org/10.1371/journal.pmed.0050046.

8. The Office of Minority Health \& Health Equity of the Centers for Disease Control and Prevention (CDC) of the USA. Available at: http://www.cdc.gov/minorityhealth/OMHHE. html. Accessed November 21, 2013.

9. Haute Autorité de Santé, Octobre 2013: recommandation sur l'utilité clinique des dosages de vitamine D. Available at: http://www.has-sante.fr/portail/jcms/c_1356838/ fr/utilite-clinique-du-dosage-de-la-vitamine-d-rapport-devaluation. Accessed November 21, 2013.

10. Haute Autorité de Santé, 4 avril 2012: Dépistage du cancer de la prostate par dosage du PSA: intérêt non démontré chez les hommes présentant des facteurs de risqué. Available at: http://www.has-sante.fr/portail/jcms/c_1238094/fr/ depistage-du-cancer-de-la-prostate-par-dosage-du-psainteret-non-demontre-chez-les-hommes-presentant-desfacteurs-de-risque. Accessed November 21, 2013.

11. Watine J, Wils J, Augereau C. Clinical Practice Guidelines: potential misconceptions of the GRADE approach. $J$ Clin Epidemiol 2014;67:7-9. http://dx.doi.org/10.1016/j. jclinepi.2013.09.001.

12. Kunz R, Schunemann HG, Guyatt G. Perceived disagreement (mostly) not confirmed by evidence. A reply to Watine et al.: Clinical Practice Guidelines: myths and misconceptions. J Clin Epidemiol 2014;67:10-4. http://dx.doi. org/10.1016/j.jclinepi.2013.09.002. 